\title{
ВЕНЧУРНАЯ АКТИВНОСТЬ В РОССИИ КАК ФАКТОР РАЗВИТИЯ ИНТЕРНЕТ- ПРЕДПРИНИМАТЕЛЬСТВА И СИСТЕМЫ ХОЗЯЙСТВЕННЫХ ВЗАИМОСВЯЗЕЙ
}

\author{
(C) 2019 Чирков Максим Андреевич \\ кандидат экономических наук, доцент кафедры политической экономии Экономического факультета \\ МГУ имени М.В. Ломоносова, Россия, Москва \\ E-mail:mospil@mail.ru
}

\section{(c) 2019 Ларина Елена Дмитриевна}

бакалавр, 4 курс, кафедра «Философия языка и коммуникации», Философский факультет

МГУ имени М.В. Ломоносова, Россия, Москва

E-mail: lenochka.larina.97@mail.ru

Интернет-предпринимательство считается одним из наиболее активно развивающихся видов бизнеса в XXI веке. Рост такой популярности не случаен, ведь данный вид предпринимательства обладает рядом преимуществ. Но, помимо большого количества плюсов, у сетевого бизнеса есть и недостатки. Например, в России основным недостатком является его низкая венчурная активность, о которой преимущественно и будет идти речь в данной работе.

В статье венчурная активность рассматривается как один из главных факторов, определяющих развитие интернет бизнеса. Венчурный капитал необходим для роста и развития новых отраслей экономики и бизнеса. К сожалению, в России не все стремятся вкладывать свои денежные средства в новые, но ещё не проверенные на практики идеи. Бизнесмены опасаются, что могут потерять свои вложения, ведь вкладывать капитал в новые отрасли всегда рискованно.

Стоит отметить, что в последнее время этот страх потери инвестиций у наших предпринимателей начинает постепенно снижаться. Они понимают необходимость вложения своего капитала в новые стартапы и бизнес проекты, которые довольно часто оказываются успешными и могут принести большую прибыль.

В статье приводится анализ, который основан на сравнение вложения капитала в новые отрасли производства за 2016-2019 гг. По данным РВК (Российская венчурная компания), мы можем видеть положительный сдвиг. На сегодняшний день, если даже сравнивать с 2016 и 2017 гг., мы получаем значительное увеличение количества вложенных венчурных активов в гранты, для разработок новых технологий производства; образование в сфере информационных технологий; бизнес проекты молодых учёных и многое другое.

За последний год увеличилось количество сделок, заключенных в области венчурного бизнеса между российскими предпринимателями и партнёрам из других стран. Этот фактор является одним из основных показателей успеха развития венчурных активов в нашей стране.

Ключевые слова: Интернет-предпринимательство, сетевой бизнес, венчурный рынок, венчурный бизнес, сфера информационных технологий, венчурная активность, информационные технологии, предпринимательство ХХІ века, бизнес ХХІ века, венчурный капитал.

\section{Введение}

Тема данной статьи достаточно актуальна. Сейчас возникает новый вид бизнеса - интернет предпринимательство [1]. Главной особенностью предпринимательства данного вида является распространение товаров и услуг не напрямую от производителя к потребителю, а также не через посредников, а с помощью такого мощного и производительного инструмента как информационная сеть, эффективность которой может быть выше большинства других каналов взаимодействия.

Актуальность данной темы также характеризуется тем, что она является довольно популярной как среди русских, так и среди зарубежных авторов. Например, Вадим Владимирович Дмитриенко - аспирант кафедры Бухгалтерского учёта и аудита, РАНХиГС при президенте РФ, 
занимался особенностями венчурного финансирования малого бизнеса в России. В своей статье «Особенности венчурного финансирования малого бизнеса в России» он особо выделяет роль государства в инновационной экономике. Государственный интерес в области венчурного инвестирования состоит в том, что венчурный капитал эффективно поддерживает малый инновационный сектор и решает задачу внедрения новых технологий в производственный процесс. Венчурная активность способствует развитию малого бизнеса, а развитие малого бизнеса является одной из наиболее приоритетных задач, которые перед собой ставит правительство РФ.

K исследованию данной проблемы так же обращался И.В. Зубков, который изучал направления государственной поддержки венчурной индустрии в России. В своей статье «Основные направления государственной поддержки венчурной индустрии в России» он выделил основные направления политики РФ, направленные на поддержание венчурного капитала: налоговое стимулирование предприятий венчурного бизнеса, содействие повышения образования и подготовки квалифицированных сотрудников в данной сфере, необходимость воспитания и прививания венчурной культуры среди предпринимателей малого и среднего бизнеса.

Исследование в рамках данной темы довольно целесообразно, так как венчурный бизнес и интернет-предпринимательство является новыми формами развития бизнеса не только в России, но и за рубежом [2]. Чтобы быть конкурентно способными в данных отраслях, необходимо провести исследование, в ходе которого должны быть выведены основные преимущества и недостатки функционирования данного бизнеса в России.

Тема данной работы достаточно нова. Так как венчурный капитал и интернет предпринимательство развиваются и функционируют не так давно, по этой теме представлено ещё не очень много научных исследований. В частности, найти статью по тематике именно государственного стимулирования венчурного бизнеса и сетевого предпринимательства очень сложно. Обычно, если и анализируют политику РФ в области экономики, то, как правило, прибегают именно к изучению некоторых общих направлений. Например, рассматривают стратегические направления России в области малого и среднего бизнеса в частности, или в области всей экономики в общем. Так же бывает, обращаются к направлению политики РФ в области образования по профилю инновационных технологий. Но, конкретного исследования политики РФ в области венчурного бизнеса и интернет предпринимательства найти практически невозможно.

Целью данной работы является показать, каким образом правительство РФ способствует развитию венчурного бизнеса и интернетпредпринимательства.

Перед нами стоит несколько основных задач. Во-первых, понять, что представляет собой венчурный бизнес и интернет-предпринимательство. Поэтому начнём исследование именно с теоретического обоснования данных понятий. Во-вторых, нам необходимо выяснить основные направления сетевого предпринимательства и венчурного бизнеса. Следующий шаг состоит в анализе основных преимуществ и недостатков данного вида предпринимательства. Далее мы рассмотрим роль правительства РФ в области сетевого бизнеса и венчурного капитала. И, наконец, в завершение, мы подведём основные итоги, которые удалось достигнуть в области венчурного бизнеса и интернет-предпринимательства, благодаря поддержке и успешной реализации политики России в данной сфере.

В данной работе наша первоочередная задача понять, что представляет собой венчурный капитал и интернет предпринимательство, поэтому начнём нашу работу именно с теоретического обоснования данных понятий, а так же дадим им основную характеристику и выделим их основные функции.

Далее важно понять, как вообще работает сетевой бизнес и венчурный капитал, а также как эти два фактор взаимодействуют между собой. И, наконец, на последнем этапе работы наша задача выяснить, какова роль государства в данной области экономики.

1. Понятие интернет-предпринимательства и его основные черты.

Интернет-предпринимательство возникает в новую (информационную) эру. В данный период у людей возникают новые потребности, для удовлетворения которых требуется не только производство иных товаров, но и новый способ их продажи и распространения от производителя к потребителю [3]. Привычные методы распространения товаров уже не так эффективно осуществляют эту задачу, поэтому возникает новый тип предпринимательства, деятельность 
которого основана на сети интернет.

Основная отличительная характеристика интернет-предпринимательства: распространение товаров и услуг не напрямую от производителя к потребителю, а также не через посредников, а с помощью такого мощного и производительного инструмента как информационная сеть, эффективность которой может быть выше большинства других каналов взаимодействия.

Активное развитие данного вида бизнеса относится к 1980-1990 годам. В 2000-х, можно сказать, что эта отрасль предпринимательства достигла своего локального пика. Ведь именно в это время активно шло активное внедрение и распространение сети интернет и электронных устройств в массовом обществе.

Предприниматели учли эти преимущества интернета и стали предлагать людям приобрести товары и услуги по интернету, что позволяло экономить время на поход по магазинам. Такой вид покупки товаров набирает все большие обороты. Это способствовало развитию крупных интернет корпораций.

Предпринимательство, основанное на сети интернет, обладает рядом преимуществ. Во-первых, в данный бизнес низкий порог вхождения [4]. Для создания реального бизнеса нужно обладать значительным капиталом, но для открытия интернет магазина достаточно лишь небольших вложений.

Второе преимущество заключается в автоматизации бизнеса. Работать в сети можно в любом месте мира. Третье преимущество заключается в том, что мы можем работать в сити круглосуточно. Четвёртое - это возможность работать с любым количеством клиентов одновременно [5]. Пятое преимущество заключается в возможности создания образа большой компании. В интернете это сделать намного проще. Ведь для ведения бизнеса в интернете вовсе не нужно арендовать шикарные офисы и дорогие магазины. Шестым плюсом является мгновенный отклик и отзыв покупателей. И, наконец, последнее существенное преимущество основано на маленькой стоимости изменений и преобразований бизнеса в сети.

Но, помимо ряда преимуществ, интернет предпринимательства в нём присутствует ряд существенных недостатков. В России самым главным недостатком является его низкая венчурная активность.

\section{2. Венчурная активность в России.}

Венчурное предпринимательство является важной составляющей всей экономической системы. Оно позволяет перейти экономики на более высокий уровень. Благодаря данному типу предпринимательства создаются новые отрасли экономики и образуются новые рабочие места. По данным НИС (национально исследовательской системе) на развитие данного предпринимательства должно приходиться не менее 25\% от ВВП. Но, по данным фонда «Сколково», в России в данную отрасль выделяется всего 7-10\% от ВВП. Такие показатели не позволяют России находиться на одной ступени развития данного вида бизнеса с Европейскими странами, США и Китаем, где ВВП в данную отрасль экономики выделяется значительно больший, чем в нашей стране.

На 2018 год, по данным РВК (Российская венчурная компания) российский венчурный рынок демонстрирует скорее позитивную динамику. В сравнение с 2017 годом он увеличился почти в два раза. На данный момент он составляет примерно 440,5 млн. долл. США. Стоит отметить, что по данным отчётов РВК на 2017 год он составлял 243,7 млн. долл. США.

Но, несмотря на эти положительные показатели, сокращается инвестиций на выдачу грантов. Если в 2016 году количество грантов составило 4651 [6], в 2017 их число сократилось до 4558 [7], то в 2018 их было выдано всего 3955 [8].

По данным фонда «Сколково», за последние три года в России не совершилось сделки, объём которой превышал бы 100 млн. долл. США. Максимальная сумма сделки в 2018 составила лишь 80 млн. долл. США.

Наибольшей популярностью у инвесторов пользуется сфера информационных технологий. Данная тенденция обусловлена развитием сетевого бизнеса, для ведения которого необходимо обладать развитым информационным и компьютерным оборудованием. По данным PBК, в данной отрасли сделки составили 86\% от общего количества сделок на венчурном рынке. Для сравнения, сильно сократилось количество инвестиций и сделок в сфере биотехнологий. Если в 2017 году их количество составляло 11, то в 2018 всего 7. В отрасли промышленных технологий наблюдается подобная динамика. В 2017 году в сфере промышленных технологий было заключено 30 сделок, а в 2018 их количество сократилось почти в два раза и составило всего 16. 
Не особой популярностью пользуется заключение сделок в области венчурного бизнеса российских инвесторов с зарубежными партнёрами. По данным анализа, который проводил фонд «Сколково» их количество в 2018 году сократилось на 20\%. Финансовый объем данных сделок составил всего 553,4 млн. долл США [9]. Но, стоит отметить, что в 2017 году по сравнению с 2016 количество, заключенных сделок возросло. В 2017 финансовый объём таких сделок составил 695,8 млн. долл США [10], тогда как в 2016 составлял всего 413, 6 млн. долл США [11].

Нельзя не отметить, что как сообщает ООО «ВЭБ Инновации» вырос средний размер венчурных сделок. Если в 2018 году сделки заключались в среднем в размере 1,5 млн. долл., то уже в первом квартале 2019 их размер увеличился до 3,1 млн. долл [12] (данные о среднем размере заключения сделок представлены в таблице и на графике «Финансовые показатели венчурного бизнеса в период 2018-1-й половины 2019 гг.»).

Как уже отмечалось ранее, в 2018 году было выдано 3955 грантов. Для сравнения с 2019 обратимся к данным первой половине 2018. В данным период было выдано в количественном объёме 2266, и было выделено финансирование в размере 37,1 млн. долл. Уже в первой половине 2019 года мы видим движение вверх в этих показателях. Например, в количественном соотношение число грантов увеличилось на $4 \%$, что составляет 2357. Что касается денежного финансирования, то здесь мы можем наблюдать более высокий скачок. Их сумма увеличилась до 46,4 млн. долл [13] (данные о выдачи грантов отражены в таблице и на графике «Финансовые показатели венчурного бизнеса в период 2018-1-й половины 2019 гг.»).

Нельзя обойти стороной тот факт, что в первом полугодии 2019, в отличие от 2018, была совершена сделка по приобретению 18,7\% акций Ozon.ru АФК «Система». Данная сделка была совершена на сумму 119,3 млн. долл, в то время, как на 2018 самая большая сделка была совершена на сумму 80 млн. долл [14] (соотношение

Финансовые показатели венчурного бизнеса в период 2018-1-й половины 2019 гг.

\begin{tabular}{|c|c|c|c|}
\hline \multirow[t]{2}{*}{ Год } & \multicolumn{3}{|c|}{ Финансовые показатели (млн. долл) } \\
\hline & Средний размер сделок & Размер выдачи грантов & $\begin{array}{c}\text { Максимальный размер } \\
\text { сделки }\end{array}$ \\
\hline 2018 & 1,5 & 37,1 & 80 \\
\hline 1-я половина 2019 & 3,1 & 46,4 & 119,3 \\
\hline
\end{tabular}

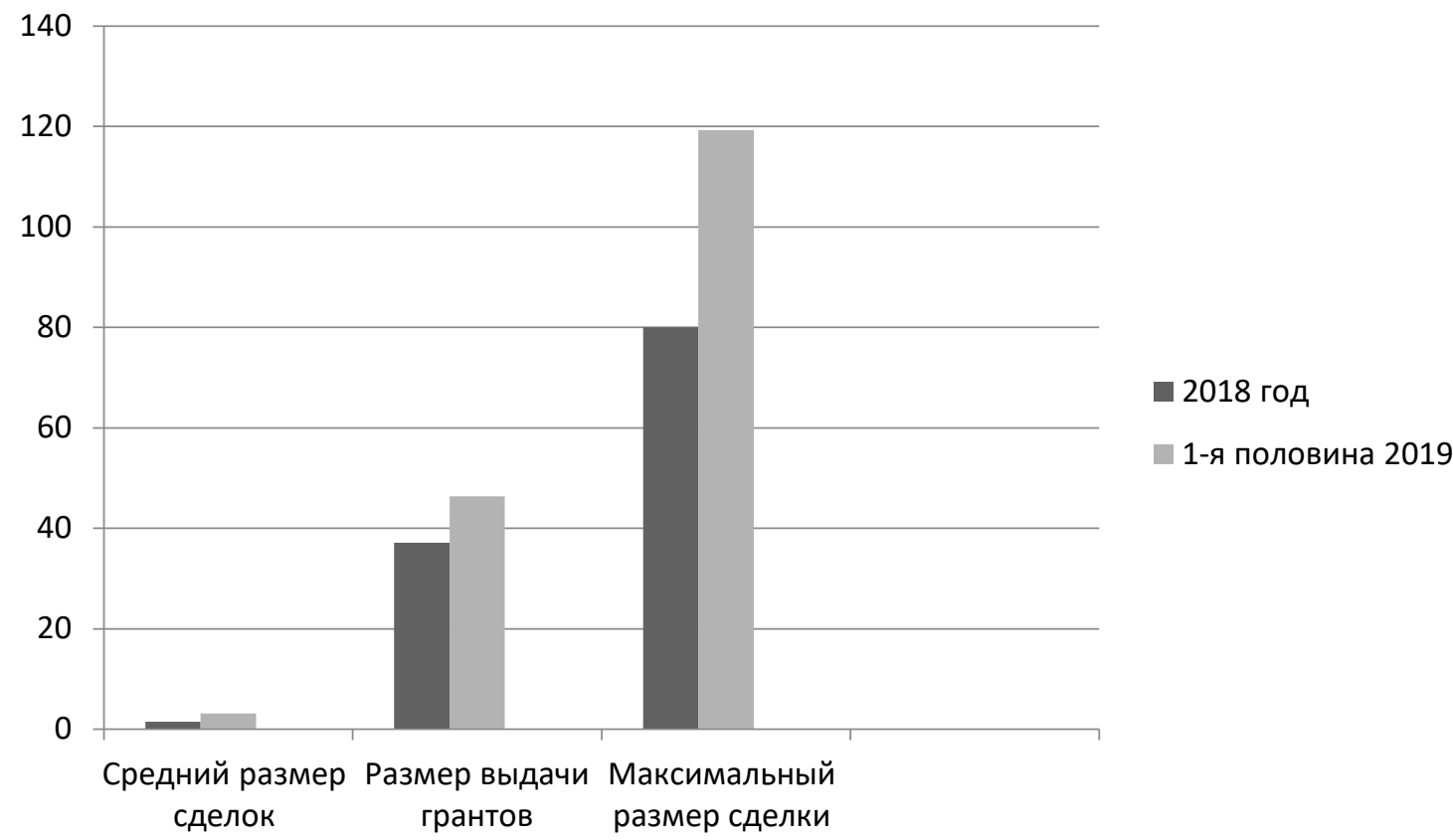

Финансовые показатели венчурного бизнеса в период 2018-1-й половины 2019 гг. 
показателей двух максимальных сделок за 2018 и 1-ю половину 2019 проиллюстрированы в таблице и на графике «Финансовые показатели венчурного бизнеса в период 2018-1-й половины 2019 гг.»).

Как уже было сказано ранее, венчурный рынок - довольно перспективная отрасль развития, которая в современном мире влияет на развитие всей экономической системы в целом. Развитие данного рынка очень важно для российской экономики. Для успешного развития данной экономической отрасли важно выстроить качественную стратегию развития и спрогнозировать пути её развития.

На данный момент РВК предлагает нам следующий стратегический проект [15]. К 2030 году стратегия развития рынка венчурных инвестиций предполагает увеличение целевых качественных и количественных показателей. В качественном показателе, во-первых, планируется увеличить годовой объём сделок на российском рынке венчурного капитала в 30 раз. Исходя из долгосрочной стратегии РВК, объем капитала в сфере венчурных инвестиций от сделок к 2030 году должен составлять около 410 млн. руб в год.

Вторая, немаловажная стратегия, заключается в увеличении суммарного предложения капитала на венчурном рынке в 10 раз. Фонд «Сколково» ориентируется на сумму 2,7 трлн. руб., предполагая увеличить количество ежегодно создаваемых высокотехнологических проектов в 2 раза. Например, компания ООО «ВЭБ Инновации» предполагает, что для успешного роста венчурного рынка их количество должно возрасти до 40 тыс.

И, наконец, последняя количественная стратегия предполагает двукратное расширение рынка сбыта инновационной продукции. По данным «Фонда содействия инновациям» их сумма должна возрасти до 10 трлн. руб.

Для увеличения качественных показателей правительство РФ разработало три основные качественные стратегии. Во-первых, необходимо повысить эффективность государственной поддержки. Как мы видим по показателям данных PBK, к сожалению, в нашей стране, начиная с 2016 года, ежегодно снижается количество выданных грантов. Такая тенденция снижает возможность внедрять в производство достойные проекты молодых учёных. К 2030, по прогнозам
PBК, в России планируется увеличить финансирование на гранты для разработок талантливой молодежи.

Вторая стратегия, ориентированная на улучшение качественного функционирования венчурной активности, предполагает организацию венчурной экосистемы вокруг ведущих технических университетов нашей страны [16]. К 20252030 гг. планируется создать исследовательскую инфраструктуру, инжиниринговые центры, бизнес-инфраструктуру: инкубаторы, технопарки и центры трансфера технологий на базе университетов. Данные компоненты присутствуют в ряде российских ведущих вузах, таких как МГу им. Ломоносова, МГТУ им. Баумана, МИФИ, СПбГУ и других высших учебных заведений, специализировавшихся в инновационных разработках. В ближайшем времени планируется улучшение инфраструктуры в передовых вузах и оснащение венчурной экосистемой региональных университетов, которые пока, к сожалению, не обладают развитой инфраструктурой.

И, наконец, третья стратегия данного направления выдвигает идею сконструировать усилия на наиболее конкурентоспособных технологических направлениях. Одним из самых приоритетных направлений является развитие информационных технологий. Именно они движущая сила прогресса и источник успеха развития интернет предпринимательства в России и за рубежом.

На первый взгляд может показаться, что венчурная активность и интернет-предпринимательство вообще не связаны между собой. Венчурный бизнес - это одна отрасль экономики, а интернет-бизнес - другая. Но на самом деле между этими двумя явлениями прослеживается тесная связь. Венчурная активность определяет развитие новых, ещё не до конца разработанных направлений бизнеса. Одним из таких направлений, безусловно, является интернет предпринимательство. От инвестиций в развитие инновационных технологий зависит функционирования всего сетевого бизнеса. Если компьютерные технологии и инновации будут развиваться на высоком уровне, то и интернетпредпринимательство примет новый толчок развития, а если данные технологии будут развиты слабо, то и функционирование интернет-бизнеса тоже будет под вопросом. 


\section{Библиографический список}

1. Кийосаки Роберт, Флеминг Джон, Ким Кийосаки. Бизнес ХХІ века. Минск: Попурри, 2018.192 с.

2. Косиненко Н.С., Фризен И.Г. Информационные системы и технологии в экономике. М.: ЮНИТИ. 2015.304 с.

3. MoneyTreеTM: Навигатор венчурного рынка (обзор венчурной индустрии России за 2018 год и первое полугодие 2019 года). URL: https://www.rvc.ru/upload/iblock/003/MoneyTree_2019_rus.pdf (дата обращения: 07.09.2019).

4. Косолапов А.Б., Елисеева Т.И. Информационные технологии в экономике и управление. М.: КноРус, 2017. 160 с.

5. Чукарин А.В., Яркина Н.В., Самуйлов К.Е. Бизнес-процессы и информационные технологии в управление современной инфокоммуникационной компанией. М.: Альпина Паблишер, 2016. 512 с.

6. Годовой отчет PBK за 2018 год. URL: https:/www.rvc.ru/press-service/news/company/ (дата обращения: 28.06.2019).

7. Годовой отчет PBК за 2017 год. URL: https://www.rvc.ru/about/docs/annual_reports/131558/ (дата обращения: 23.04.2018).

8. Годовой отчет PBК за 2016 год. URL: http://www.rvc.ru/about/docs/annual_reports/109384/ (дата обращения: 16.05.2017).

9. Годовая бухгалтерская (финансовая) отчетность РВК за 2016 год. URL: http://www.rvc.ru/about/disclosure/ godovaya-bukhgalterskaya-finansovaya-otchetnost/Godovoy_buh_finans_otchet_2016.pdf (дата обращения: 25.05.2017).

10. Годовая бухгалтерская (финансовая) отчетность PBК за 2017 год. URL: https://www.rvc.ru/disclosure/ godovaya-bukhgalterskaya-finansovaya-otchetnost/Godovoy_buh_finans_otchet_2017.pdf (дата обращения: 29.04.2018).

11. Годовая бухгалтерская (финансовая) отчетность PBK за 2018 год. URL: https://www.rvc.ru/about/disclosure/ godovaya-bukgalterskaya-finansovaya-otchetnost/Godovoy_buh_finans_otchet_2018.pdf (дата обращения: 03.07.2019).

12. Отчет PBК на первое полугодие 2019 года. URL: https:/www.rvc.ru/analytics/ (дата обращения: 06.11.2019).

13. Развитие экосистем вузов и научных центров. РВК. Санкт-Петербург. URL: https://www.rvc.ru/upload/ iblock/06b/innovation_ecosystem_analytical_report.pdf (дата обращения: 15.02.2019).

14. Преимущества инвестирования в российский инновационный сектор. URL: http://www.rvc.ru/upload/ iblock/9e4/investment_benefits.pdf (дата обращения: 08.08.2019).

15. Актуальные тренды развития российских быстрорастущих технологических компаний. URL: https://www. rvc.ru/upload/iblock/5d7/ratingtechup_2018.pdf (дата обращения: 16.02.2019).

16. Ясенев В.Н. Информационные системы и технологии в экономике. М.: ЮНИТИ, 2018. 506 с. 